\title{
War Syndromes: The Impact of Culture on Medically Unexplained Symptoms
}

\author{
EDGAR JONES and SIMON WESSELY*
}

The general principle that the experience of combat damages servicemen's long-term physical and mental health is recognized. ${ }^{1}$ However, controversy has raged over the nature of particular post-combat disorders such as shell shock, disordered action of the heart (DAH), effort syndrome, effects of Agent Orange and, not least, Gulf War syndrome. ${ }^{2}$ We, among many others, have argued that they should be classified as functional syndromes ${ }^{3}$ characterized by medically unexplained symptoms, ${ }^{4}$ which include: fatigue, weakness, sleep difficulties, headache, muscle ache and joint pain, problems with memory, attention and concentration, nausea and other gastro-intestinal symptoms, anxiety, depression, irritability, palpitations, shortness of breath, dizziness, sore throat and dry mouth. ${ }^{5}$ Despite popular claims to the contrary, no simple biomedical aetiology has been discovered to account for these disorders, hence the term "medically unexplained". ${ }^{6}$ Furthermore, they are not easily interpreted using accepted psychiatric classifications. Without demonstrable organic cause, war syndromes have attracted diverse causal explanations, ranging from pressure on the arteries of the chest, constitutional inferiority, toxic exposure, bacterial infection to microscopic cerebral haemorrhage.

One area of understandable confusion is the relationship between conventional psychiatric disorders, in particular post-traumatic stress disorder (PTSD), and syndromes characterized by medically unexplained symptoms. This lack of clarity is hardly surprising since

\section{(C) Edgar Jones and Simon Wessely 2005}

*Professor Edgar Jones and Professor Simon Wessely, Department of Psychological Medicine, Institute of Psychiatry and King's College London, Weston Education Centre, 10 Cutcombe Road, London SE5 9RJ; e-mail: E.Jones@hogarth7.demon.co.uk; s.wessely@iop.kcl.ac.uk

The authors wish to thank Susie Kilshaw for her helpful discussion of the text. Thanks are also due to Professor Harry Lee for granting access to anonymized patient records at the Gulf Veterans Medical Assessment Programme. The study was funded by a grant from the US Army Medical Research \& Materiel Command, Fort Detrick, Maryland. Both authors were members of the expert witness team appointed by the Ministry of Defence in its successful defence of a PTSD class action in the High Court. Tables 1 and 2 are reproduced with kind permission of the British Medical Journal.

\footnotetext{
${ }^{1}$ G H Elder, M J Shanahan, and E C Clipp, 'Linking combat and physical health: the legacy of World War II in men's lives', Am. J. Psychiatry, 1997, 154: 330-6.
}

\footnotetext{
${ }^{2}$ B Shephard, War of nerves: soldiers and psychiatrists 1914-1994, London, Jonathan Cape, 2000; H Binneveld, From shell shock to combat stress: a comparative history of military psychiatry, Amsterdam University Press, 1997.

3 "Functional" is used to describe disorders in which the presumed physiological basis of symptoms is not the result of structural or pathological change in the body. Rather such symptoms are considered to be a consequence of the way that a person's physiological systems function, a matter in modern terminology of software rather than hardware.

${ }^{4} \mathrm{~A} J$ Barsky and J F Borus, 'Functional somatic syndromes', Ann. Intern. Med., 1999, 130: 910-21; C Bass, R Peveler and A House, 'Somatoform disorders: severe psychiatric illnesses neglected by psychiatrists', Br.J. Psychiatry, 2001, 179: $11-14$.

5 A J Barsky, 'The paradox of health', N. Engl. J. Med., 1988, 318, 414-18.

${ }^{6} \mathrm{~S}$ Wessely, C Nimnuan and M Sharpe, 'Functional somatic syndromes: one or many?' Lancet, 1999, 354: 936-9.
} 


\section{Edgar Jones and Simon Wessely}

both can arise in the context of warfare. PTSD, first recognized as a legitimate psychiatric diagnosis in $1980,{ }^{7}$ is defined in psychological terms as a disorder of traumatic memory, featuring nightmares, intrusive recollections and flashbacks (which overlap with the normal ways in which veterans remember their experiences), but also behaviourally since these features lead to avoidance and impaired social interaction. Hence, PTSD is distinct from functional somatic syndromes, such as irritable heart or DAH, which are defined by the presence of multiple, clinically-significant somatic symptoms but do not require overt psychological experiences such as nightmares or avoidant behaviour. However, these somatic disorders are associated, but are not synonymous, with anxiety and depression. ${ }^{8}$

Culture is an elusive phenomenon but has been defined as "systems of meaning" that "are necessarily the collective property of a group". ${ }^{9}$ In essence, it refers to learned patterns of thought and behaviour characteristic of a given population. Culture, perhaps, has its greatest opportunity to influence the form of, and meaning attached to, medical disorders when scientific experiment and clinical investigation have failed to define or identify their aetiology. Functional somatic syndromes, which arise in the context of traumatic experience thereby evoking powerful feelings, may be particularly prone to the impact of such forces.

Edward Shorter argued that individuals possess a "symptom repertoire", which is available to both the conscious and unconscious mind for the physical expression of psychological conflict. ${ }^{10}$ Particular symptoms may appear in specific periods partly as a result of underlying cultural trends. At a societal level, popular health fears alert patients to particular areas of the body and can offer explanations that resonate with widely shared beliefs. Servicemen during the Second World War, for example, may have tended to emphasize gastro-intestinal symptoms because of the general fear of peptic ulcer. Not only would dyspepsia and stomach pain convey a sense of seriousness, they would plausibly gain the attention of a regimental medical officer primed to invalid men who might break down in action. At a professional level, doctors are likely to look for, or to emphasize, symptoms that fall within their specialist area or are considered significant at the time. A gastroenterologist will tend to look for stomach-related symptoms and pay less attention to muscular and joint pains than, say, a rheumatologist. ${ }^{11}$ Given the rising incidence of peptic ulcer during the 1940s and the risk of death from perforation, physicians paid particular attention to dyspepsia in individuals who might serve in situations without ready access to emergency medical services. The very real difficulties of making an accurate diagnosis, often led to multiple and varied investigations. In the mind of the serviceman, this attention may have reinforced any belief that his gut pain had a life-threatening cause. Thus, the selection of symptoms, the weight that is attached to them and the explanations that follow from both doctors and patients were likely to have been subject to cultural forces.

Furthermore, it is hypothesized that the form taken by war syndromes was influenced by the evolving nature of combat: not least the effect of new technology on weaponry but also the impact of "modernity" in Weberian terms of the growth and differentiation of

\footnotetext{
${ }^{7}$ American Psychiatric Association, Diagnostic and statistical manual of mental disorders (DSM-III). Washington, DC, APA, 1980, p. 238.

${ }^{8} \mathrm{~K}$ Kroenke, and R Price, 'Symptoms in the community: prevalence, classification and psychiatric comorbidity', Arch. Intern. Med., 1993, 153: $2474-80$.
}

\footnotetext{
${ }^{9}$ C Geertz, The interpretation of culture, New York, Basic Books, 1973, pp. 12-13.

${ }^{10}$ E Shorter, 'Paralysis: the rise and fall of a "hysterical” symptom', J. soc. Hist., 1986, 19: 549-82, p. 549.

${ }^{11}$ Wessely, Nimnuan and Sharpe, op. cit., note 6 above, pp. 936-9.
} 


\section{War Syndromes}

bureaucracy; the application of standardization and routine to administrative action; and the employment of experts to define and order such systems. ${ }^{12}$ The role of the soldier and his place in society plausibly influenced the behaviour of veterans and the explanations offered for such post-combat disorders as they experienced.

Although considerable research has been directed towards the cultural history of PTSD ${ }^{13}$ war syndromes have been somewhat neglected. Some studies have assumed that PTSD is, in effect, a modern re-interpretation of popular diagnoses of earlier wars. Dean argued, for example, that the symptoms of PTSD, including flashbacks, can be identified in the accounts of veterans of the American Civil War. ${ }^{14}$ Indeed, some have argued that railway spine and shell shock were simply PTSD by other names. ${ }^{15}$ Furthermore, there is a "Whiggish" tendency, notable in the quasi-historical accounts of some contemporary trauma specialists, to assume that PTSD trumps all previous conditions as we move in a steady progression from ignorance to post DSM-III enlightenment.

In this paper we seek to assess the impact of culture on the expression and interpretation of functional somatic syndromes during the Boer War, First and Second World Wars and the Gulf conflict. Medically-unexplained symptoms are explored in their own right and not simply as the putative ancestors of PTSD. We will then compare evidence derived from random samples of servicemen suffering from war syndromes with contemporary accounts in an attempt to understand the form of these disorders.

\section{Method}

The statistical investigation on which this paper is based has already been published and the methodology and results are reiterated in their simplest form to provide a basis for a wider discussion. ${ }^{16}$ To identify symptom patterns, random samples of veterans diagnosed with post-combat disorders typical of particular conflicts were selected. War pension files were used as the primary source because they contained detailed medical and military reports. The assessment procedure for soldiers did not change greatly over the period, though the criteria were revised. After 1916, awards were no longer based on a veteran's ability to earn a living wage but were granted according to a standardized schedule of injury in which, for example, the loss of two or more limbs entitled a man to a 100 per cent pension. ${ }^{17}$

\section{Selection of Subjects}

All the surviving pension files for Boer War veterans, formerly administered by the Royal Hospital, Chelsea, are held at the National Archives (PIN71). An analysis of

\footnotetext{
${ }^{12} \mathrm{R}$ Cooter and S Sturdy, 'Of war, medicine and modernity', in R Cooter, M Harrison and S Sturdy (eds), War, medicine and modernity, Thrupp, Stroud, Sutton Publishing, 1998, pp. 1-21, on p. 7.

${ }^{13}$ A Young, The harmony of illusions: inventing post-traumatic stress disorder, Princeton University Press, 1995.

${ }^{14}$ E T Dean, Shook over hell: post-traumatic stress, Vietnam, and the Civil War, Cambridge, MA, Harvard University Press, 1997, pp. 107-8, 130-1.

${ }^{15} \mathrm{~S}$ Joseph, R Williams and W Yule,

Understanding post-traumatic stress: a psychosocial perspective on PTSD and treatment, Chichester, John
}

Wiley, 1997, p. 6; M R Trimble, 'Post-traumatic stress disorder: history of a concept', in C R Figley (ed.), Trauma and its wake. Vol. 1: The study and treatment of post-traumatic stress disorder, New York, Brunner/Mazel, 1985, p. 5.

${ }^{16}$ E Jones, R Hodgins-Vermaas, H McCartney, B Everitt, C Beech, D Poynter, I Palmer, K Hyams and S Wessely, 'Post-combat syndromes from the Boer War to the Gulf War: a cluster analysis of their nature and attribution', Br. med. J., 2002, 324: 321-4.

${ }^{17}$ E Jones, I Palmer and S Wessely, 'War pensions (1900-1945): changing models of psychological understanding', Br. J. Psychiatry, 2002, 180: 374-9. 


\section{Edgar Jones and Simon Wessely}

mortality rates and serial numbers showed that these are not a complete holding. The 6,276 files represent some of the longest-lived or more severe cases. Because the catalogue listed pensioners alphabetically without recording their diagnosis, it was necessary to examine every file. To generate representative samples, consecutive cases were extracted in proportion to their alphabetical distribution by surname. In this way 200 cases of disordered action of the heart (DAH) or valvular disease of the heart (VDH), where subsequent reports and death certificates indicated a functional disorder, were gathered, together with 200 cases of rheumatism (in the absence of organic signs such as inflammation and joint swelling). Whilst surveying the archive, a few pensioners were discovered who had served in Victorian campaigns, notably Afghanistan, Egypt and the Sudan. Twenty-eight of these had functional somatic disorders, which fell into two broad diagnostic groups: cardiac (19), which included "palpitation" and "irritable heart", and debility (9).

The only surviving war pension records from the First World War are held at the National Archives (PIN26). The 22,756 cases in the holding are based on the London Region of the Ministry of Pensions, which under the decentralized system of May 1919 acquired responsibility for South East England. ${ }^{18}$ The sampling exercise had been undertaken by War Pensions staff, who probably chose the London Region as the largest and most accessible holding. They selected every fiftieth file to create a 2 per cent sample. On this basis, the 22,756 files were extracted from 1,137,800 records. An official report calculated that by March 1930, 1,644,000 pensions or gratuities had been granted to veterans of the First World War, ${ }^{19}$ which suggests that the London Region represented about 60 per cent of the total number of pensions and gratuities awarded for the conflict. The catalogue, which is organized alphabetically by recipient, was placed into a database and analysed by diagnosis. Using a random-number generator, samples of 200 cases of DAH (to provide a direct comparison with the Boer War) and 200 cases of shell shock, or neurasthenia as it was re-classified in 1917, were selected. The proportions of officers to other ranks for DAH and neurasthenia were adjusted to reflect their distribution within the total population. In addition, a random selection of 167 servicemen who had been gassed without permanent organic injury were included. In total, 305 pensions granted to nurses have survived; all awards for DAH and neurasthenia were included.

The task of creating a random sample of servicemen who had been gassed but not suffered long-term physical damage was more complex. A catalogue survey revealed 279 veterans awarded a war pension for the effects of gas or gas poisoning. A systematic examination of these cases indicated that many showed the symptoms of serious exposure to toxic gases with identifiable damage to lungs, skin and eyes. Soldiers who had lesser exposures and no lasting objective signs and yet suffered from unexplained symptoms were often re-categorized by doctors as DAH. ${ }^{20}$ It was necessary, therefore, to examine all 279 veterans with a pension for gassing to distinguish the organic cases from the functional ones.

\footnotetext{
${ }^{18}$ T D Rhind, 'Decentralisation', War Pensions Gazette, 1919, 25: 307-10.

${ }^{19}$ T J Mitchell and G M Smith, History of the Great War, based on official documents, medical services, London, HMSO, 1931, pp. 103, 315.
}

\footnotetext{
${ }^{20} \mathrm{~J} \mathrm{C}$ Meakins and T M Walker, Reports of the Chemical Warfare Medical Committee, No. 7, Changes observed in the heart and circulation and the general after-effects of irritant gas poisoning, London, Medical Research Committee, 1918, pp. 19-26.
} 


\section{War Syndromes}

Approximately 30 per cent proved to have objective signs of toxic exposure and were excluded from the investigation. A further 20 per cent had incomplete or limited medical files and were also excluded. This gave a total of 143 cases. To obtain a sample of significant size, DAH files were selected using a random-number generator to identify veterans who had been gassed. Twenty-four such servicemen were added to the sample in this fashion, bringing the total to 167 .

Pension files relating to the Second World War and subsequent conflicts are closed to public inspection and were held by the War Pensions Agency. Ministerial permission was obtained to gather anonymized data from these records. The files are stored chronologically from the time that they were awarded and sub-divided between the three services and between officers and other ranks. The other ranks' files are divided into two groups: those that applied for a pension between 1939 and 1942 and who were assessed on a regional basis (133,500 files), and those that applied between 1942 and 1945 and were assessed centrally (750,000 files). These central files are further divided into two groups: M2 and M6. The M2 series continued chronologically from the old regional centres and covers the years 1943 to 1945. The M6 series was created in 1945 to deal with servicemen released (rather than discharged) from the forces at the end of the war. These soldiers were released rapidly either because of their length of service, because their skills were urgently needed in industry, or on compassionate grounds. The M6 series was discontinued in 1950. In addition, there are 215,000 files in payment, relating to the Second World War. The structure of the archive has important implications for the design of the sample, as different periods of the war saw different groups of servicemen granted pensions. Awards in the first year, for example, were often to elderly territorials or re-enlisted regulars who found active service too stressful. Before the selection and training of troops became carefully controlled, many conscripts were discharged from the forces because their educational, psychological or physical attributes made them unable to cope with the rigours of training. ${ }^{21}$ The Normandy campaign of 1944 saw many seasoned troops break down, some war-weary after earlier combat in Africa and Italy. To reflect the various changes that occurred to the pension population during the war, files were randomly extracted to equate with the proportions of the archive.

Three diagnostic groups were chosen: effort syndrome (for comparison with the Boer War and First World War samples of DAH) and psychoneurosis (for comparison with shell shock/neurasthenia). To reflect the change in medical priorities from the heart to the gut, 100 cases of non-ulcer dyspepsia were also randomly selected. Relatively few pensions were awarded for effort syndrome and all cases were included.

Considerable problems were encountered in finding awards for psychoneurosis, effort syndrome and dyspepsia from the Korean War and campaign in Malaya in part because troops deployed there represented a small proportion of the UK's armed forces. All cases were included. Although pensions have been granted to veterans of the Gulf War, we were not granted permission to consult these files. Nevertheless, it was important to study a group who believed that their health was damaged by military service. The Ministry of Defence granted access to anonymized case records from the Gulf Veterans' Medical Assessment

\footnotetext{
${ }^{21}$ E Slater, 'War neurosis', Br. med.J., 1942, i: 421.
} 


\section{Edgar Jones and Simon Wessely}

Programme at St Thomas' Hospital. From their database of 2162 army personnel, a sample of 400 Gulf veterans was selected using a random-number generator.

Medical notes in war pension files were in most cases detailed and covered the serviceman's history from enlistment until demise; death certificates were often included. Veterans were required to attend regular medical boards to assess their disability and specialist opinions were sought. As a result, symptoms were recorded throughout an individual's military service and after discharge. The long-term nature of the notes allowed cases to be excluded if a serviceman was found to be suffering from an organic disorder or a major mental illness. Prisoners-of-war were not included because of the psychological stress they experienced and the nutritional deficits which many had suffered. The investigation was restricted to members of the British army. A total of 1856 subjects were included drawn from six conflicts and representing ten diagnoses (Table 1).

For each subject biographical and military details were recorded, together with a possible 94 symptoms extracted from medical notes taken during service and, where possible, for a decade after discharge from the forces. The 94 symptoms were then reduced to the 25 most common and the resulting dataset of 1856 soldiers subjected to cluster analysis.

\section{Table 1}

The database: total number of cases by war and diagnosis

\begin{tabular}{lc}
\hline War and disorder & Number of service personnel \\
\hline Victorian Campaigns (1854-c.1895) & 19 \\
1. Palpitation & 9 \\
2. Debility & 200 \\
Boer War (1899-1902) & 200 \\
1. DAH & \\
2. Rheumatism & 200 \\
First World War (1914-18) & 200 \\
1. DAH & 167 \\
2. Neurasthenia & \\
3. Gassed & 24 \\
Nurses & 49 \\
1. DAH & \\
2. Neurasthenia & 67 \\
Second World War (1939-45) & 200 \\
1. Effort Syndrome & 100 \\
2. Psychoneurosis & \\
3. Dyspepsia & 1 \\
Malaya (1948-60) and Korea (1951-53) & 15 \\
1. Effort syndrome & 5 \\
2. Psychoneurosis & \\
3. Dyspepsia & 400 \\
Gulf War (1991) & \\
Gulf-related illness & \\
Total &
\end{tabular}




\section{War Syndromes}

With the exception of the Gulf War sample, the evidence for this study was derived from war pension records. In practice, these files had been used to establish whether a veteran was entitled to financial compensation and, if a dispute occurred, could form the subject of an appeal or, more rarely, a court case. As a result, claimants had a vested interest in reporting symptoms and may on occasion have exaggerated their severity and number. By contrast, the examining doctors, who were employed by the Ministry of Pensions, were instructed to test the veracity of these claims and to look for signs of recovery. Pensioners were required to attend an annual board composed of two or more doctors until the disability was regarded as stable. Thereafter assessments were more sporadic unless the veteran believed that his condition had deteriorated. War pension case notes contain inherent bias but we have no evidence to suggest that these competing forces changed in any significant respect over the period of this investigation.

\section{Results}

The analysis identified three clusters of post-combat syndromes: a debility cluster $(\mathrm{n}=847)$, a somatic cluster $(\mathrm{n}=434)$ and a neuropsychiatric cluster $(\mathrm{n}=575)$. Although a significant statistical difference was found between the three clusters (Table 2), there was considerable overlap in the presentation of symptoms. The debility cluster was characterized by fatigue, difficulty completing tasks, shortness of breath and weakness, while rapid heartbeat, tremor, headache, dizziness, pains in joints, difficulty sleeping, changes in weight and anxiety were moderately represented. Psychological and neurological symptoms, such as depression, memory impairment, irritability and poor concentration were notably absent. The somatic cluster was typified by rapid heartbeat, shortness of breath, fatigue and dizziness. Difficulty completing tasks, headache, tremor and anxiety were moderately represented. This symptom cluster was indicative of a functional cardiac syndrome.

Although a range of bodily symptoms (shortness of breath, tremor, pains in joints, back pain, excessive sweating and rapid or irregular heartbeat) were prominent in the neuropsychiatric cluster, it was distinguished from the somatic group by a range of psychological

Table 2

Distribution of syndrome clusters by war

\begin{tabular}{lcccr}
\hline War & $\begin{array}{c}\text { Debility } \\
\text { syndrome }\end{array}$ & $\begin{array}{c}\text { Somatic } \\
\text { syndrome }\end{array}$ & $\begin{array}{c}\text { Neuropsychiatric } \\
\text { syndrome }\end{array}$ & Total \\
\hline Victorian campaigns & $23(82)$ & $4(14)$ & $1(4)$ & $28(100)$ \\
Boer War & $308(77)$ & $91(23)$ & $1(0.3)$ & $400(100)$ \\
First World War & $292(46)$ & $213(33)$ & $135(21)$ & $640(100)$ \\
Second World War & $76(21)$ & $83(23)$ & $208(57)$ & $367(100)$ \\
Malaya/Korea & $2(10)$ & $5(24)$ & $14(67)$ & $21(100)$ \\
Gulf & $146(37)$ & $38(10)$ & $216(54)$ & $400(100)$ \\
Total & 847 & 434 & 575 & 1856
\end{tabular}

$\left(\mathrm{x}^{2}\right.$-square $=523, \mathrm{df}=10, \mathrm{p}$ value $\left.=<0.001\right)$.

Figures in brackets indicate percentages. 


\section{Edgar Jones and Simon Wessely}

Table 3

Contemporary diagnosis

\begin{tabular}{lcccr}
\hline Diagnosis & $\begin{array}{c}\text { Debility } \\
\text { syndrome }\end{array}$ & $\begin{array}{c}\text { Somatic } \\
\text { syndrome }\end{array}$ & $\begin{array}{c}\text { Neuropsychiatric } \\
\text { syndrome }\end{array}$ & Total \\
\hline Cardiac & $15(79)$ & $4(21)$ & $0(0)$ & $19(100)$ \\
Debility & $8(89)$ & $0(0)$ & $1(11)$ & $9(100)$ \\
DAH & $255(60)$ & $166(39)$ & $3(1)$ & $424(100)$ \\
Rheumatism & $173(87)$ & $26(13)$ & $1(1)$ & $200(100)$ \\
Neurasthenia & $86(35)$ & $33(13)$ & $130(52)$ & $249(100)$ \\
Gassed & $86(52)$ & $79(47)$ & $2(1)$ & $167(100)$ \\
Psychoneurosis & $17(8)$ & $17(8)$ & $181(84)$ & $215(100)$ \\
Effort syndrome & $23(34)$ & $30(44)$ & $15(22)$ & $68(100)$ \\
Dyspepsia & $38(36)$ & $41(39)$ & $26(25)$ & $105(100)$ \\
Gulf-related illness & $146(36)$ & $38(10)$ & $216(54)$ & $400(100)$ \\
Total & 847 & 434 & 575 & 1856 \\
\end{tabular}

$\left(\mathrm{x}^{2}\right.$-square $=796, \mathrm{df}=16, \mathrm{p}$ value $\left.=<0.001\right)$.

Figures in brackets indicate percentages.

symptoms, including fatigue, headache, depression, anxiety and difficulty sleeping. In addition, difficulty completing tasks, forgetfulness, dizziness, weakness, irritability, poor concentration, jumpiness, changes in personality, nightmares and weight change were moderately represented.

Using logistic regression analysis, an underlying association was detected between war (in effect, chronology) and clusters of symptoms. The debility syndrome was largely drawn from veterans of late Victorian campaigns, the Boer War and First World War. The somatic syndrome represented First World War with subsidiary elements from the Boer War and Second World War. The neuropsychiatric cluster was predominantly composed of Second World War and Gulf War servicemen.

Cluster membership was cross-classified against contemporary diagnosis. Because diagnosis tends to follow changes in medical knowledge and cultural developments, the temporal pattern identified in the analysis by war is also apparent from this variable (Table 3 ). For example, functional cardiac disorders (palpitation, irritable heart, DAH and effort syndrome) were little understood until the First World War and had been a major cause of discharge from the British army. Cluster one has 57.3 per cent of all functional cardiac disorders cases, cluster two 39.1 per cent and cluster three 3.5 per cent. By comparison, psychological disorders (neurasthenia and psychoneurosis), which became increasingly recognized as the twentieth century progressed, are distributed as follows: cluster one 22.2 per cent, cluster two 10.8 per cent and cluster three 67 per cent.

\section{The Medical Expression of War Syndromes}

Both generic terms, "war syndrome" and "post-combat disorder", are of recent origin, and somewhat misleading insofar as they have been applied to servicemen who have broken down in training or when deployed to the comparative safety of rear echelons. It is important 


\section{War Syndromes}

to distinguish them from what was termed battle exhaustion or combat fatigue and is now known as combat stress reaction. These are the immediate effects of battle and manifested by an inability to function largely because of physical and mental fatigue. Such cases can develop into post-combat disorders if a serviceman fails to recover after a short period of rest and rehabilitation. Because it has only recently been proposed that a common theme runs through these war syndromes, ${ }^{22}$ each campaign tended to generate its own specific label. To what extent, therefore, do contemporary diagnostic terms, ideas of aetiology and changes in the technology of warfare explain the three clusters that have been identified?

\section{Focus on the Heart}

Symptoms relating to the heart (palpitation, chest pain and shortness of breath) are prominent in both the debility and somatic clusters, which relate to disorders of the late nineteenth and early twentieth century. Military medicine in this period struggled to explain growing numbers of heart disorders for which no organic cause could be found. A variety of terms were employed, including soldier's heart, irritable heart, palpitation and later disordered action of the heart, reflecting the general confusion. Jacob Da Costa (18331900), who had studied the phenomenon during the American Civil War, ${ }^{23}$ concluded that there was no clear-cut cause, though his analysis of 200 cases (selection criteria were not stated) showed that 38.5 per cent had been subject to "hard field service and excessive marching", a further 30.5 per cent had previously suffered from diarrhoea. ${ }^{24}$

Cases of palpitation had been recorded by the British army during the Crimea, though discharges became a serious cause for concern in 1864 following a presentation at the Royal United Services Institute by W C Maclean (d. 1898), professor of military medicine at the Army Medical School, Netley. Although Britain was not then at war, these soldiers had broken down either under the rigours of training or when serving overseas, particularly in India. Subsequently, Maclean surveyed 5500 soldiers admitted to the Royal Victoria Hospital, Netley, who had served abroad between 1863 and 1866, and found that almost 10 per cent had been discharged from the forces with a heart disorder. ${ }^{25}$ Having excluded rheumatism, excessive alcohol consumption, heavy smoking or over-exertion as causes, Maclean considered that the weight and distribution of the soldier's equipment were responsible: "the present accoutrements are highly injurious to the health of infantry soldiers and have a large share in producing many affections of the lungs and heart common among them". ${ }^{26} \mathrm{He}$ argued that webbing supporting a pack constricted the major blood vessels to and from the heart forcing it to pump excessively hard to maintain circulation. Having reached a similar conclusion, the 1865 War Office inquiry recommended the

\footnotetext{
${ }^{22}$ K C Hyams, F S Wignall and R Roswell, 'War syndromes and their evaluation: from the U.S. Civil War to the Persian Gulf War', Ann. Intern. Med., 1996, 125: $398-405$.

${ }^{23}$ Charles F Wooley, 'Jacob Mendez DaCosta: medical teacher, clinician and clinical investigator', Am. J. Cardiol., 1982, 50: 1145-8.

${ }^{24} \mathrm{~J}$ M Da Costa, 'On irritable heart: a clinical study of a form of functional cardiac disorder and its consequences', Am.J.med.Sci., 1871, 121:2-52, p. 37; see also Dean, op. cit., note 14 above, pp. 130-1;
}

\footnotetext{
Charles F Wooley, The irritable heart of soldiers and the origins of Anglo-American cardiology: the US Civil War (1861) to World War I (1918), Aldershot, Ashgate Publishing, 2002, pp. 12-15.

${ }^{25} \mathrm{~W}$ C Maclean, 'Diseases of the heart in the British Army: the cause and the remedy', Br. med. J., 1867 , i: $161-4$.

${ }^{26} \mathrm{~W}$ C Maclean, 'The influence of the present knapsack and accoutrements on the health of the infantry soldier', Journal of the Royal United Service Institution, 1864, 8: 105-15.
} 


\section{Edgar Jones and Simon Wessely}

redesign of equipment affecting the chest. ${ }^{27}$ The marked differences in incidence between units, Maclean believed, related to illness behaviour: "in well-disciplined regiments the practice of falling out at drill or on the line of march is discouraged, and men will bear and suffer much, rather than incur the imputation of being "soft", 28

A further survey of 1635 cardiac admissions to Netley Hospital between 1863 and 1869 by A B R Myers, assistant surgeon to the Coldstream Guards, found that 1322 (80.9 per cent) were discharged from the forces and only 276 (16.9 per cent) returned to duty. ${ }^{29}$ Having concluded that heart disorders were "more prevalent in the army than the civil population", Myers concluded that three factors accounted for this difference: rheumatic fever, Bright's disease and violent manual labour. He too pointed a finger at the soldier's equipment:

His waist-belt adds to the constriction below the chest, and his tunic collar above it ... and then, to complete the artificial chest case, the knapsack straps supply all that is requisite, whilst the pouchbelt adds its share to the general compression. The chest, thus fixed as it were in a vice, has little or no power of expansion, and the circulation through the heart, lungs and great vessels is proportionately impeded. ${ }^{30}$

Concern in the UK mounted in 1876 when re-designed equipment failed to prevent new cases of irritable heart. Indeed, the Royal Hospital, Chelsea, awarded some ex-servicemen disability pensions for "palpitation" after the Afghan War of 1879 and the various campaigns in Egypt (1882-89) and the Sudan (1896-97). ${ }^{31}$ Despite this evidence that there was an association with combat, Surgeon Arthur Davy suggested that the setting-up drill caused an over-expansion of the chest, which in turn produced dilatation of the heart thereby inducing "irritability". ${ }^{32}$ Hence, late-nineteenth-century studies of DAH attempted to identify a mechanical pathology, whether hypertrophy, valvular lesion or aortic dilatation, and proposed mechanical causes, commonly an obstruction of the heart's outflow. ${ }^{33}$ Because there was no effective treatment of these supposed organic conditions, servicemen were simply discharged, while investigators continued to search for ways to prevent new cases.

Disordered action of the heart was a major cause of invalidity during the South African campaign of 1899-1902. According to official statistics, 3631 servicemen were hospitalized with DAH, and of these 41 per cent were invalided to the UK where they were generally discharged. ${ }^{34}$ The highest incidence of DAH was reported in orderlies of the Royal Army Medical Corps, explained by the great distances that field units were required to march to support fighting battalions. ${ }^{35}$ In the latter stages of the war, a large number of

\footnotetext{
${ }^{27}$ Report of the Committee appointed to inquire into the effect on the health of the present system of carrying the accoutrements, ammunition, and kit of infantry soldiers, and drill \& . of recruits, London, HMSO, 1865 , pp. 7, 9 .

${ }^{28}$ Maclean, op. cit., note 26 above, p. 111.

${ }^{29}$ A B R Myers, On the etiology and prevalence of diseases of the heart among soldiers, London, John Churchill, 1870, p. 4.

${ }^{30}$ Ibid., pp. 32-3.

${ }^{31}$ The National Archives (NA), PIN71/257 Frederick Dickerson, 71/588 Robert McLaughlin, 71/2446 Charles East, 71/3142 Harry Haslop, 71/1424 Thomas Bishop, and 71/2972 A. Grubb.
}

\footnotetext{
${ }^{32} \mathrm{R}$ McNair Wilson, 'The irritable heart of soldiers', Br. med. J., 1916, i: 119-20.

${ }^{33}$ J D Howell, 'Soldier's heart: the redefinition of heart disease and speciality formation in early twentieth century Great Britain', in Cooter, Harrison and Sturdy (eds), op. cit., note 12 above, pp. 85-105, on pp. 86-7.

${ }^{34} \mathrm{~T}$ J Mitchell and G M Smith, Medical services, casualties and medical statistics of the Great War, London, HMSO, 1931, p. 273.

${ }^{35}$ Sir W D Wilson, Report on the medical arrangements in the South African War, London, HMSO, 1904, p. 71.
} 
small columns were deployed against the Boers so that medical units had long periods of continuous marching to keep up with the widely spread engagements. It was concluded that the prolonged strain of carrying heavy weights and the pressure of straps on the chest had damaged the heart. An official report also argued that "cardiac exhaustion cases were much more frequent among men of volunteer companies than the regulars, probably due to the great difference of their usual daily occupation from the life of a soldier on active service" 36 - an observation that would be repeated during the next century. Once a soldier had succumbed to DAH, it was noticed that the symptoms returned if he had to "undergo any extra exertion, or from the excitement or nervousness of going under fire". These cases also increased in number "if the physical strength of the men cannot be kept up by good and sufficient food and the necessary amount of sleep and rest". ${ }^{37}$ Thus, the important connection between battle fatigue and continuous exposure to combat had been observed but its implications not fully understood.

Although heavy smoking was thought to play a contributory part in DAH, the trend from rural to industrial recruits was now identified as a significant cause: "the ill-fed, anaemic, under-sized and somewhat neurotic lads, of which the larger cities produce so plentiful a supply as compared with the sturdy, somewhat lethargic country lad". ${ }^{38}$ Indeed, the scandal, much canvassed by politicians and journalists, over the apparently poor physique of potential recruits during the Boer War led to the setting up of the Inter-Departmental Committee on Physical Deterioration in $1904 .^{39}$ Its report argued that the problem was bound geographically and socially to the poor of the slums and that the principal cause was overcrowding. ${ }^{40}$ Ironically, it was the widespread nature of shell shock and other war syndromes during the First World War that helped to undermine the traditional distinction between the hereditarily fit and unfit. When officers were found to suffer disproportionately from the disorder, mental illness could no longer be conceived in the restricted realm of degenerates with weak hereditary constitutions. ${ }^{41}$

Although shell shock was the quintessential war syndrome of 1914-18, soldier's heart or DAH did not disappear. Howell has argued that military physicians, under the leadership of Thomas Lewis, re-defined the disorder as "effort syndrome" in a way that was "more consistent both with acute wartime exigencies and with an ongoing transformation of the concept of heart disease from static and anatomical to dynamic and physiological". ${ }^{42}$ In the opening phases of the war, for example, the disorder was hypothesized not in terms of improper drill and faulty equipment but as a result of excessive glandular secretions or infectious micro-organisms. Early in 1916, Sir James Mackenzie argued that the privations of trench warfare not only weakened men's constitutions but also provided a suitable habitat for toxic bacteria. ${ }^{43}$ The net result, he believed, was a state of general exhaustion and that heart abnormalities were not cardiac in origin, but the outcome of injury to the central

\footnotetext{
${ }^{36}$ Ibid., p. 73.

${ }^{37}$ Ibid.

${ }^{38}$ Anon, Report of the Army Medical Department, London, HMSO, 1912, p. 9.

${ }^{39}$ D Pick, Faces of degeneration: a European disorder, c. 1848-c. 1918, Cambridge University Press, 1989, p. 185.
}

\footnotetext{
${ }^{40}$ Inter-Departmental Committee on Physical Deterioration, Report, in Reports from

commissioners, inspectors and other series, PP 1904, XXXII, p. 17.

${ }^{41}$ Pick, op. cit., note 39 above, pp. 231-2.

${ }^{42}$ Howell, op. cit., note 33 above, p. 85 .

${ }^{43}$ Sir J Mackenzie, 'The soldier's heart', $B r$. med. $J ., 1916$, i: $117-19$.
} 


\section{Edgar Jones and Simon Wessely}

nervous system. ${ }^{44}$ This interpretation had parallels in the late-nineteenth-century idea that neurasthenia was a consequence of influenza or typhoid infection. Despite the existence of toxic or post-infective explanatory models, these did not achieve widespread popularity in contrast to the latter part of the twentieth century when they were used to account for the effects of Agent Orange and Gulf War syndrome.

Specialist military hospitals were set up in Hampstead and Colchester under Thomas Lewis to research these hypotheses. ${ }^{45}$ Although he was unable to discover the cause of DAH, Lewis ruled out a number of organic factors, including valvular lesions. By the end of the war, he had identified three possible pathological mechanisms: decreased buffer salts in the blood, an increased leucocyte count, and a difference in urinary constituents (increased calcium and oxalic acid together with decreased urea). ${ }^{46}$ However, none of these hypotheses were mentioned in the 1940 edition of Lewis's The soldier's heart and the effort syndrome, which suggests that further investigation had failed to establish a connection. Lewis did retain his conviction that this was a disorder of functional capacity and that the symptoms represented "exaggerated manifestations of the healthy responses to effort". ${ }^{47}$ In his 1917 report, Lewis recommended that terms such as irritable heart and DAH be replaced by "effort syndrome" because they conveyed the "meaning of a primary cardiac disorder". Graded exercises were used not only to assess the severity of the disorder but as a treatment, soldiers being encouraged at each increment of exertion.

\section{Rheumatism}

During the Boer War, rheumatism, or muscle and joint pain associated with fatigue, became prominent causes of invalidity. "Among the symptoms we find prominently," recalled Anthony Bowlby (1855-1929), a civil surgeon, who had worked at the Portland Hospital in Rondebosch and Bloemfontein during 1900, were "pain, in the form of headache, generally posterior, pains in the neck, pains in the back and limbs, so that these cases are generally sent back as cases of rheumatism; general feebleness of the muscular system amounting to paralysis more or less pronounced". ${ }^{48}$ The Boer War saw 24,460 troops admitted to hospital with rheumatic fever or rheumatism, of whom 4305 were evacuated home. Although today rheumatic fever, a disease that can cause heart failure, is differentiated from non-articular rheumatism, a disorder characterized by subjective symptoms (joint pain, stiffness and tenderness), physicians in the nineteenth century were unable or unwilling to draw such a definite distinction.

A systematic investigation of the war pension files administered by the Royal Hospital, Chelsea, has shown that most veterans who had been awarded a pension for rheumatism showed no objective signs of the disease within a few years of discharge.

\footnotetext{
${ }^{44} \mathrm{C}$ F Wooley, 'From irritable heart to mitral valve prolapse: World War I, the British experience and James Mackenzie', Am. J. Cardiol., 1986, 57: 463-6.

${ }^{45} \mathrm{C}$ F Wooley, 'From irritable heart to mitral valve prolapse: World War I, the British experience and Thomas Lewis', Am. J. Cardiol., 1986, 58: 844-9.

${ }^{46}$ A J Christophers, 'The epidemic of heart disease amongst British soldiers during the First World War', War and Society, 1997, 15: 53-72.
}

\footnotetext{
${ }^{47} \mathrm{~T}$ Lewis, Report upon soldiers returned as cases of "Disordered Action of the Heart" (D.A.H.) or "Valvular Disease of the Heart" (V.D.H.), London, HMSO, 1917, p. 7.

${ }^{48}$ A A Bowlby, $\mathrm{H}$ H Tooth, C Wallace, J E Calverley and Surgeon-Major Kilkelly, A civilian war hospital. Being an account of the work of the Portland Hospital, and of experience of wounds and sickness in South Africa, 1900, London, John Murray, 1901, p. 129.
} 


\section{War Syndromes}

Dr J W Washbourn, who ran the Imperial Yeomanry Hospital at Pretoria in the latter stages of the war, treated 296 cases of chronic muscular rheumatism (the fourth most common medical disorder there) but was unable to establish a connection with rheumatic fever. At a loss to explain the phenomenon, Washbourn considered that it was the result of "the men's food and especially the want of fresh vegetables". ${ }^{49}$ A more common explanation offered by both men and RAMC doctors was that exposure to cold and wet on the veldt was the primary cause of rheumatic pains. Because the cardiac complications of rheumatic fever were then untreatable and often led to invalidity and premature death, pains in muscles and joints were a focus of concern for both patients and doctors.

\section{Shell Shock}

Although shell shock has become a synonym for the trauma of trench warfare, no unambiguous definition of the disorder exists. ${ }^{50}$ The closest attempt was made in the report of the Southborough Committee: "emotional shock, either acute in men with a neuropathic predisposition, or developing slowly as a result of prolonged strain and terrifying experience, the final breakdown being sometimes brought about by some relatively trivial cause. [Or] nervous and mental exhaustion, the result of prolonged strain and hardship". ${ }^{51}$ In practice, shell shock was characterized by medically un-explained symptoms: tics, paresis, tremor, contractures, fatigue, headache, sleep difficulties, nightmares, memory loss, poor concentration and general bodily aches and pains. As such, it bore little resemblance to the modern definition of PTSD. ${ }^{52}$

As regards causation, it was initially hypothesized that there were two varieties of shell shock: commotional and emotional. Frederick Mott (1853-1926), pathologist to the London County Council asylums, categorized it as a form of "commotio cerebri" with a defined physical aetiology. He suggested that the forces of compression and decompression, resulting from proximity to an explosion, in turn led to microscopic brain haemorrhage. ${ }^{53} \mathrm{He}$ also believed that carbon monoxide released by the blast might lead to cerebral poisoning. When it became apparent that many of those soldiers with the symptoms of shell shock had not been close to an explosion, and some not even in combat, Mott accepted the idea of an emotional category. Such individuals with "an inborn or acquired disposition to emotivity" could become so affected by the stress of battle, or its prospect, to "be rendered unconscious or so dazed as to necessitate them being taken or carried to the clearing station". 54

\footnotetext{
${ }^{49} \mathrm{~J}$ W Washbourn, 'Some of the principal diseases met with among the troops in South Africa during the present war', Lancet, 1901, ii: 394-5, p. 394.

${ }^{50} \mathrm{~J}$ Bourke, Dismembering the male: men's bodies, Britain and the Great War, London, Reaktion Books, 1996, pp. 107-13; P Leese, Shell shock, traumatic neurosis and the British soldiers of the First World War, Basingstoke, Palgrave Macmillan, 2002, pp. 159-61.

${ }^{51}$ Lord Southborough, Report of the War Office Committee of Inquiry into 'shell-shock', London, HMSO, 1922, p. 92.
}

\footnotetext{
${ }^{52}$ E Jones, R Hodgins-Vermaas, H McCartney, C Beech, I Palmer, K Hyams and S Wessely, 'Flashbacks and post-traumatic stress disorder: the genesis of a twentieth-century diagnosis', $\mathrm{Br}$. $J$. Psychiatry, 2003, 182: 158-63.

${ }^{53} \mathrm{~F}$ W Mott, 'Special discussion on shell shock without visible signs of injury', Proceedings of the Royal Society of Medicine, 1916, 9: i-xxiv.

${ }^{54}$ F W Mott, 'War neuroses', Br. med. J., 1919, i: $439-42$, p. 439 .
} 


\section{Edgar Jones and Simon Wessely}

By contrast, a psychological interpretation of shell shock came from medical officers who had first-hand experience of war in France. Captain Harold Wiltshire, who until August 1915 had been responsible for the diagnosis of functional psychiatric cases at No. 12 General Hospital in Rouen, observed that:

Gradual psychic exhaustion from continued fear is an important disposing cause of shell shock, particularly in men of neuropathic predisposition. In such subjects it may suffice to cause shell shock per se. In the vast majority of cases of shell shock, the exciting cause is some special psychic shock. Horrible sights are the most frequent and potent factor in the production of this shock. Losses and the fright of being buried are also important in this respect. ${ }^{55}$

C S Myers, a medically-qualified psychologist, proposed that functional symptoms, such as loss of memory, partial paralysis or mutism, were expressions of a traumatic experience of which the servicemen could not consciously admit. He believed that an individual had to acquire "volitional control" over memories of these events "if he is to be healed". 56 Almost as soon as shell shock was interpreted as a psychological, rather than a physical, injury, efforts were made to suppress use of the term. Fearing that it would open a floodgate to malingerers and war pension claimants, Sir Arthur Sloggett, Director-General of Medical Services of the British Armies in the Field, ruled in December 1916 that the term was to be discouraged in favour of "Not Yet Diagnosed, Nervous" (NYDN), while strict guidelines were laid down for the clinical management of such cases. ${ }^{57}$

Special "NYDN Centres" were set up about ten miles from the front line in France to treat soldiers by physical methods: rest followed by graduated exercise. If a serviceman failed to respond to treatment and was discharged from the forces, the war pension authorities opted for the diagnosis of neurasthenia, though if heart symptoms predominated a claimant could be re-classified as DAH or effort syndrome. While shell shock disappeared from medical terminology (and was actively proscribed in 1939), ${ }^{58}$ it gathered strength during the interwar period in popular usage. By comparison, effort syndrome, DAH and, its American variant, neurocirculatory asthenia (NCA), all of which continued to be used in medical literature, did not strike the same cultural chord and gradually fell into disuse as they were superseded by other diagnostic terms.

In terms of symptoms, shell shock combined that traditional focus on the heart with a comparatively novel range of neuropsychiatric symptoms. Senses were sometimes affected: men could not hear or see and experienced strange smells, tastes and inexplicable pain. Their physical and mental functioning was also impaired; some could not speak or walk, while their cognitions were affected by nightmares, intrusive thoughts and difficulty concentrating. This was a broader range of symptoms than had been indicated after Victorian campaigns and the Boer War and seemed to express the effects that men felt on their psychological well-being. Indeed, Chris Feudtner had showed how shell shock cases, often volunteers and men with unblemished characters, forced both physicians and the public to begin to question their conception of mental illness as an outcome of constitutional

\footnotetext{
${ }^{55} \mathrm{H}$ Wiltshire, 'A contribution to the etiology of shell shock', Lancet, 1916, i: 1207-12, p. 1212.

${ }^{56} \mathrm{C} \mathrm{S}$ Myers, 'Contributions to the study of shell shock, being an account of certain cases treated by hypnosis', Lancet, 1916, i: 65-9, p. 69.
}

\footnotetext{
${ }^{57}$ Shephard, op. cit., note 2 above, p. 139.

${ }^{58}$ B Shephard, "Pitiless psychology": the role of prevention in British military psychiatry in the Second World War', Hist. Psychiatry, 1999, 10: 491-524.
} 


\section{War Syndromes}

degeneration. "The old dichotomy of sanity and madness simply could not address the questions of the age". ${ }^{59}$ A similar conclusion was reached by Ted Bogacz, who argued that the widespread incidence of shell shock "challenged long-held medical opinions about the nature and treatment of mental illness", while also threatening "a number of traditional moral values", 60

\section{Second World War: Effort Syndrome and Non-Ulcer Dyspepsia}

From being an unexplained form of heart disease to a functional disorder with psychological features, the status of effort syndrome was transformed by three papers published by Paul Wood in the British Medical Journal during $1941 .^{61}$ By comparing a sample of 175 soldiers admitted to the effort syndrome unit at Mill Hill EMS Hospital with a control population of militiamen, he demonstrated that men with functional cardiac symptoms exhibited a heightened emotional response to stressful activity. Wood concluded that the division into sub-types of effort syndrome (constitutional, induced, post-infective, psychoneurotic and physically fatigued) was "misleading if not meaningless". ${ }^{62}$ Effort syndrome, he argued was "an emotional reactive pattern peculiar to psychopathic personalities and to subjects of almost any form of psychoneurosis". ${ }^{63}$ Whilst the aftermath of the Second World War did not witness an epidemic of pensions for effort syndrome, Maxwell Jones, Wood's psychiatric collaborator at Mill Hill, observed in 1946 that "there is no reason to assume that the condition has become less common-it is simply that the diagnosis E.S. is out of favour; psychiatrists in this country prefer to classify patients according to their psychiatric disability rather than their effort intolerance". ${ }^{64}$

Outwardly, a significant change appeared to have taken place in the physical focus of war syndromes, related not simply to the discrediting of effort syndrome. In 1945, Roy Grinker and John Spiegel observed that "gastrointestinal symptoms flourish in an abundance and variety", contrasting with "the frequent cardiac syndromes observed in the last war". ${ }^{65}$ By 1941 the incidence of non-ulcer dyspepsia had become a "major medical problem" for the UK armed forces. ${ }^{66}$ In May 1942, digestive disorders accounted for 17 per cent of all discharges for diseases from the army and airforce. ${ }^{67}$ At first, it was hypothesized that dyspepsia represented a new entity akin to shell shock at the beginning of the First World War; others suggested that it was due to an acute type of peptic ulceration. Yet, studies soon showed that the incidence of ulcer in the civilian population had been growing steadily

\footnotetext{
${ }^{59} \mathrm{C}$ Feudtner, " "Minds the dead have ravished": shell shock, history, and the ecology of diseasesystems', Hist. Sci., 1993, 31: 377-420, p. 410.

${ }^{60} \mathrm{~T}$ Bogacz, 'War neurosis and cultural change in England, 1914-22: the work of the War Office committee of enquiry into "shell-shock", J. contemp. Hist., 1989, 24: 227-56, p. 227.

${ }^{61} \mathrm{P}$ Wood, 'Da Costa's syndrome (or effort syndrome)', Br. med. J., 1941, i: 767-72; idem, 'Da Costa's Syndrome (or effort syndrome): the mechanism of the somatic manifestation', $\mathrm{Br}$. med. J., 1941, i: 805-11; idem, 'Aetiology of Da Costa's syndrome’, Br. med. J., 1941, i: 845-51.
}

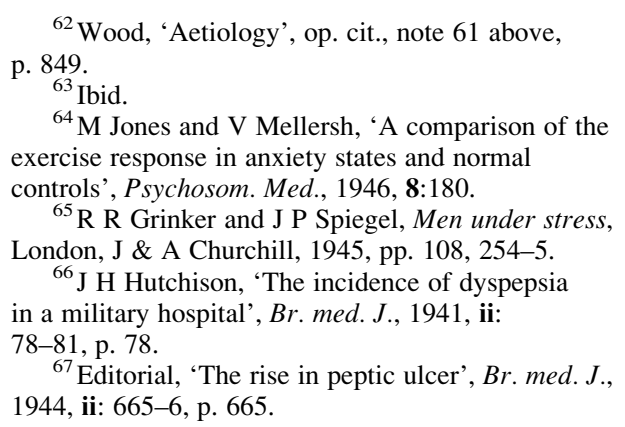




\section{Edgar Jones and Simon Wessely}

during the inter-war period and that most servicemen with gastric symptoms had suffered from them before enlistment. These findings led to the conclusion that most cases were of old-standing peptic ulceration, which had broken down under the conditions of active service. ${ }^{68}$ At a time when diagnostic tools were at best unreliable, gastroenterologists and radiologists tended to err on the side of caution. Estimates of those with peptic ulcer among the large numbers of servicemen suffering from chronic dyspepsia ranged from 89 per cent of 201 cases invalided from France ${ }^{69}$ to 45.5 per cent of 88 consecutive UK admissions. ${ }^{70}$ A 1941 study, which included veterans of Dunkirk and the Lofoten raid, found an incidence of 64.2 per cent in 246 servicemen admitted to a military hospital with gastro-intestinal pain. The authors concluded that a change in dietary habits together with the stress of adopting to a new lifestyle were responsible. ${ }^{71}$ It is interesting that the most obvious explanation, the intense stress of combat, was not explored.

In March 1941, H L Tidy, consultant physician to the Royal Military Hospital, Millbank, speaking at a special conference held by the Royal Society of Medicine, identified two potential causes: irregular mealtimes and the heavier nature of army food. ${ }^{72}$ Psychological factors were excluded because "peptic ulcer and all dyspeptic disturbances were noticeably rare" during the First World War when similar stresses arguably operated. Not everyone agreed with this conclusion. C A Hinds Howell reported 131 cases of "neurotic dyspepsia" in 1941 at a UK military hospital, an increase of 12.4 per cent over the figure for $1940 .{ }^{73}$ By contrast, he proposed a constitutional explanation:

Those people of poor personality who in peacetime are only just able to accommodate themselves to their home environment are no longer able to do so when this is changed on enlistment to the discipline of Army environment. Whether it is pure chance that their neurosis is centred on their digestion it is difficult to say. ${ }^{74}$

Although studies conducted at the beginning of the war excluded psychological explanations, increasing contact with patients led to a re-evaluation. An analysis of the social class and lifestyles of peptic-ulcer mortalities led J N Morris and R M Titmuss to conclude that duodenal ulcer was a psychosomatic disorder related to a particular "hypothalamic" type of personality. They considered that the stresses of metropolitan life, rather than nutritional factors, played a key causal role. ${ }^{75}$

Retrospective studies, based on mortality statistics, established that the war years witnessed an epidemic of peptic ulceration, which rose to a peak prevalence in the-mid 1950s. ${ }^{76}$ During the Second World War, there was no effective treatment, apart from risky gastrectomy, so that peptic ulcer became "known and feared by the laity as a cause of incapacity

\footnotetext{
${ }^{68}$ Editorial, 'Dyspepsia in the army', Br. med. J., 1940, ii: 836-7.

${ }^{69} \mathrm{R}$ T Payne and C Newman, 'Interim report on dyspepsia in the army', Br. med. J., 1940, ii: 819-21.

${ }^{70}$ Hutchison, op. cit., note 66 above, 79.

${ }^{71} \mathrm{~J}$ G Graham and J D O Kerr, 'Digestive disorders in the forces', Br. med. J., 1941, i: 473-6, p. 475.

${ }^{72} \mathrm{H}$ L Tidy, 'Discussion on dyspepsia in the armed forces', Proc. R. Soc. Med., 1941, 34: 413-14; idem, 'Peptic ulcer and dyspepsia in the army', $B r$. med. J., 1943, ii: 473-7.
}

${ }^{73} \mathrm{C}$ A Hinds Howell, 'A comparison of dyspepsia in the army for 1940 and 1941', Br. med.J., 1942, i: $692-3$.

${ }^{74}$ Ibid., p. 693.

${ }^{75} \mathrm{~J}$ N Morris and R M Titmuss, 'Epidemiology of peptic ulcer, vital statistics', Lancet, 1944, ii: 841-5, p. 841.

${ }^{76} \mathrm{M}$ J S Langman, The epidemiology of chronic digestive disease, London, Edward Arnold, 1979, p. 15. 


\section{War Syndromes}

and sometimes fatal complications". ${ }^{77}$ It was also appreciated that complex investigations could be counterproductive. An editorial in the Lancet for August 1945 observed that "in gastric disorders which come short of actual ulceration army experience has shown that even hospital investigation and the ritual of barium meal examination fix the susceptible soldier's attention increasingly on his stomach and help to perpetuate 'functional' symptoms". ${ }^{78}$ This suggests that "pure chance" was probably not the explanation for the increase in non-ulcer dyspepsia during the Second World War and that the form taken by conversion disorders were influenced by popular health fears and limitations of medical science.

Using the example of hysterical paraplegia, Shorter showed that this disorder was doomed once neurologists had developed accurate neurophysiological methods to distinguish between organic and psychological causation. ${ }^{79}$ This example suggests that it is unlikely that non-ulcer dyspepsia will ever again be a prominent medically unexplained syndrome. The discovery of histamine $\mathrm{H}_{2}$-antagonists as an effective treatment of peptic ulcer in $1976,{ }^{80}$ subsequent research into the pathological role of Helicobacter pylori and the development of accurate endoscopic techniques have removed any doubt or mystery surrounding stomach disorders.

While cultural forces played an important part in the presentation and recognition of symptoms, they were not the sole factor. It is significant that cluster analysis did not reveal a gastro-intestinal group composed in the main of veterans of the Second World War. Indeed, soldiers diagnosed with non-ulcer dyspepsia are distributed between all three clusters, though to a lesser extent in the neuropsychiatric group. Similarly, ex-servicemen with a diagnosis of shell shock/neurasthenia are not to be found in a single cluster associated with the First World War. Some of them have symptom patterns in common with Gulf War veterans and men who fought in the Boer War. These results suggest that the actual symptom patterns of war syndromes are diverse and less focused on bodily areas than contemporary descriptions and interpretations have suggested. By no means were all sufferers of war syndromes in the First World War troubled by the symptoms of shell shock, and many manifested the traditional cardiac picture of DAH. Effort syndrome endured well into the Second World War when stomach problems and psychological symptoms were thought to dominate post-combat syndromes. It appears therefore that culture may play less of a part in determining symptom patterns than has been suggested. Its main impact may relate to the ways that physicians categorize and interpret functional somatic presentations, and the ways that patients act on and explain their symptoms. Thus, culture can often condition a novel medical explanation that satisfies most of society at a particular time but at the cost of ignoring exceptions and continuities.

\section{Second World War: Psyche over Soma}

The incidence of somatoform disorders, common during the First World War and before, is widely stated to have fallen during the Second World War. ${ }^{81} \mathrm{~J}$ A Hadfield,

\footnotetext{
${ }^{77}$ Editorial, 'Doctor-made', Lancet, 1945, ii: 240.

${ }^{78}$ Ibid.

${ }^{79}$ Shorter, op. cit., note 10 above, pp. 564-6.

${ }^{80}$ Edgar Jones, The business of medicine, London, Profile Books, 2001, pp. 334-6.
}

\footnotetext{
${ }^{81}$ S A MacKeith, 'Lasting lessons of overseas military psychiatry', J. Mental Health, 1946, 92: 548-9; A S Walker, Clinical problems of war, Canberra, Australian War Memorial, 1952, p. 283; M Culpin, 'Clinical psychology and
} 


\section{Edgar Jones and Simon Wessely}

who worked at No. 41 General (Neuropathic) Hospital, regarded "the far greater proportion of anxiety states ... as against conversion hysteria (blindness, paralysis etc.)" as "the most striking change" between the two conflicts. Of the 700 servicemen admitted over a period of ten months, he calculated that 53 per cent had a diagnosis of anxiety compared with 24 per cent who had a functional somatic disorder. Hadfield cited the "thousands of 'shell-shocked' patients who returned from the Somme and other great battles" as evidence for a greater preponderance of hysteria. ${ }^{82}$ Without objective measures and statistical analysis of overseas and UK military hospitals, it is impossible to substantiate this claim. However, the epidemic of non-ulcer dyspepsia witnessed during the Second World War suggests that Hadfield overlooked an important category of patients. It is by no means certain that somatoform disorders were displaced by overt psychological presentations, rather it appears that they assumed a different disguise.

Yet Hadfield's view was widely held. An editorial in the British Medical Journal for 30 June 1945 declared:

"Disordered action of the heart" - a favourite diagnosis in the last war-has given place to "effort syndrome"; and now that that has been shown by Paul Wood, [T.] Lewis, M. Jones and others to be in every respect the equivalent of an anxiety neurosis, it too has lost favour and has become a rare diagnosis. No longer do we talk of "shell shock": the organic approach has given place to a preference for psychological interpretation. ${ }^{83}$

More recently, Joanna Bourke has argued that "unlike the First World War when hysterical reactions greatly outnumbered fear reactions, from 1940 there were epidemics of acute anxiety". ${ }^{84}$ This apparent change from physical to psychological symptoms was explained by administrative measures to outlaw diagnoses such as shell shock, the discrediting of effort syndrome and because servicemen were increasingly made aware of unconscious mechanisms in so-called "war neuroses" through education and psychotherapy. ${ }^{85}$ Hence, it remains conventional wisdom that as psychological enlightenment spread during the twentieth century, psychiatric models for unexplained symptoms gained ascendancy over more intellectually suspect organic claims. To support this contention, it is claimed that hysteria, once common, has now almost vanished from the western world. ${ }^{86}$ An alternative suggestion is that the former popularity of the diagnosis was a cultural phenomenon, which may be unrelated to real changes in the incidence of hysteria, ${ }^{87}$ a view supported by common presentation of conversion disorders in neurological, rather than psychiatric, practice.

some forgotten episodes', Br. med. J., 1952, ii: 955-6, p. 956.

${ }^{82} \mathrm{~J}$ A Hadfield, 'War neurosis: a year in a neuropathic hospital', Br. med. J., 1942, i: 281-5, p. 281.

${ }^{83}$ Editorial, 'Progress in the psychiatry of war', Br. med. J., 1945, i: 913-14, p. 913.

${ }^{84} \mathrm{~J}$ Bourke, 'Disciplining the emotions: fear, psychiatry and the Second World War', in Cooter, Harrison, and Sturdy (eds), op. cit., note 12 above, pp. 225-38, on p. 226.

\footnotetext{
${ }^{85} \mathrm{~J}$ Rickman, 'A case of hysteria: theory and practice in the two world wars', Lancet, 1941, i: 785-6; J R Neill, 'How psychiatric symptoms varied in World War I and II', Mil. Med., 1993, 149: $149-51$.

${ }^{86}$ I Veith, Hysteria: the history of a disease, University of Chicago Press, 1965.

${ }^{87}$ M Micale, 'On the "disappearance of hysteria": a study in the clinical deconstruction of a diagnosis', Isis, 1993, 84: 496-526.
} 


\section{War Syndromes}

\section{Gulf War Syndrome: Toxic Exposures}

During the Second World War, no post-combat syndrome had been explained in terms of toxic exposure and indeed, apart from men who had been gassed, poisonous substances were not implicated in the First World War or the Boer War. The only exception was perhaps the use of atebrin in South East Asia, as a prophylaxis against malaria, which some Australian troops believed was the cause of impotence, a claim that was to be echoed by Gulf veterans. ${ }^{88}$ With Vietnam a significant change took place in the attribution of causality. Dioxin (Agent Orange), a defoliant, was sprayed from aircraft over the jungle that provided cover for the Vietcong. Agent Orange derived its name, not from the chemical itself, as was popularly believed, but the colour of the drums in which it was stored. Some veterans suffering from chronic somatic symptoms attributed their illness to the effects of herbicide exposure, while it was also claimed to have been the cause of birth defects in their children. ${ }^{89}$ Indeed, the Vietnam Veterans Association of Australia suggested that exposure to Agent Orange could have led to a form of "toxic neurasthenia". 90 To date, scientific and epidemiological studies have failed to identify a causal link. ${ }^{91}$ However, it is noteworthy that the somatic symptoms frequently described by veterans who were exposed to Agent Orange were similar to symptoms commonly associated with other war-related illnesses. ${ }^{92}$ Exposure to Agent Orange reflected contemporary fears that organic solvents and other chemical compounds could provoke a widespread sensitivity crisis in the body, sometimes involving the immune system. These ideas found civilian expression in sick building syndrome, mercury poisoning syndrome and multiple chemical sensitivities (MCS), autoimmune diseases and dysregulation of immunological processes caused by modern synthetic chemicals. ${ }^{93}$

Desert Storm syndrome, or Gulf War syndrome as it more popularly became known, has also attracted a range of causal hypotheses, most of which involve exposure to a toxic agent that is unseen or disguised, difficult to detect and potent in its effects. ${ }^{94}$ Candidates included side effects of multiple vaccinations, smoke from oil-well fires, depleted-uranium shells, chemical and biological warfare, and organophosphate pesticides. ${ }^{95}$ These explanations reflect powerful cultural themes, and represent civilian concerns translated into a military context. Fears over DU poisoning are related to a general fear of radiation, vaccinations are widely mistrusted as the concern over the MMR has demonstrated, while society's fear of chemical pesticides has, in part, encouraged organic methods of farming.

\footnotetext{
${ }^{88}$ Walker, op. cit., note 81 above, pp. $127-8$.

${ }^{89}$ Dean, op. cit., note 14 above, pp. 16-17.

${ }^{90} \mathrm{~W}$ Hall and D MacPhee, 'Do Vietnam veterans suffer from toxic neurasthenia?' Aust. NZJ.P sychiatry, 1985, 19: 19-29.

${ }^{91}$ Institute of Medicine (U.S.), Veterans and Agent Orange: health effects of herbicides used in Vietnam, Washington, DC, National Academy Press, 1994; C A Boyle, P Decouffle and T R O'Brien, 'The long-term health consequences of military service in Vietnam', Epidemiol. Rev., 1989, 11: 1-27; H A Lee, R Gabriel, J P G Bolton, A J Bale and M Jackson, 'Health status and clinical diagnoses of 3000 Gulf War veterans', J. R. Soc. Med., 2002, 95: 491-7.
}

\footnotetext{
${ }^{92} \mathrm{C}$ Holden, 'Agent Orange furor continues to build', Science, 1979, 205: 770-2.

${ }^{93}$ E Shorter, 'Multiple chemical sensitivity: pseudodisease in historical perspective', Scand. J. Work Environ. Health, 1997, 23 suppl 3: 35-42; C V Ford, 'Somatization and fashionable diagnoses: illness as a way of life', Scand.J. Work Environ. Health, 1997, 23 suppl 3: 7-16.

${ }^{94}$ E Showalter, Hystories: hysterical epidemics and modern culture, London, Picador, 1997, pp. 135-36.

${ }^{95}$ A David, S Ferry and S Wessely, 'Gulf War illness', Br. med. J., 1997, 314: 239-40; H A Lee, $\mathrm{R}$ Gabriel and R Bolton, 'Depleted uranium-is it really a health issue?', Lancet Oncology, 2001, 2: 197.
} 


\section{Edgar Jones and Simon Wessely}

\section{The Changing Nature of Warfare}

The technology of war and tactical ideas changed dramatically over the period of this study. Troops who fought in the Boer War were often required to march considerable distances to engage the enemy; it was a war of movement without mechanization. Contemporaries believed that the physical exertion involved was, in part, responsible for the various heart disorders encountered. Similarly, shell shock was framed in terms of trench warfare: an expression of the terror felt by men forced to endure passively the effects of artillery bombardment. Although not the subject of this paper, air combat produced its own varieties of post-combat disorder: "flying stress", "aviation neurasthenia" and later "lack of moral fibre", which initially were attributed to anoxia, the result of flying in rarified air. The technical nature of modern warfare, and in particular the threat of chemical and biological weapons, is expressed by the symptoms (headache, poor concentration and memory impairment) and explanations surrounding Gulf War syndrome. Not only do the diagnostic labels attached to war syndromes reflect the changing nature of combat, so too do the causal hypotheses advanced by veterans and doctors.

An analysis of the military records of servicemen in our study, together with war diaries, revealed that the percentage involved in actual fighting fell over time as the proportion of troops in combat-support roles has risen. Of the Boer War veterans, 77 per cent had been in combat, of the First World War pensioners 73.4 per cent, of the Second World War sample 52 per cent, while only 19.8 per cent of the Gulf War sample had seen action. War syndromes arose therefore not only in servicemen who fought but also in those faced with the prospect of battle.

\section{Attributions by Servicemen}

How, then, did servicemen themselves explain their war syndromes? Applicants for a war pension were required to state what they thought was the cause of their disability. In addition, doctors recorded patient statements at subsequent assessments. In the main, there were six categories of explanation that symptoms were: (1) the result of a physical illness acquired while in the army; (2) the result either of a physical injury or the physical strain of campaigning (marching, sleeping on hard ground, completing assault courses); (3) the result of an adverse climate (wet and cold in South Africa) or environment (the heat of the Western Desert or monsoon jungle of Burma); (4) the result of a toxic exposure: either to gas in the First World War or chemical and biological weapons or depleted-uranium ordnance in the Gulf War; (5) the result of psychological stress caused by combat or the prospect of combat; (6) the result of psychological stress caused by distance from family and friends or particular home worries.

An analysis of pensioners' explanations suggested that attributions were culturally conditioned and varied across the century tied to prevailing health beliefs and concerns (Table 4). Boer War servicemen diagnosed with DAH generally believed it to be the result of either physical illness (25.5 per cent) or of physical exertion (24.5 per cent). A different pattern emerged in the First World War with physical exertion accounting for 45.0 per cent of the DAH sample and 42.5 per cent of the neurasthenia group. However, a significant number of the latter (34.0 per cent) attributed their symptoms to the 


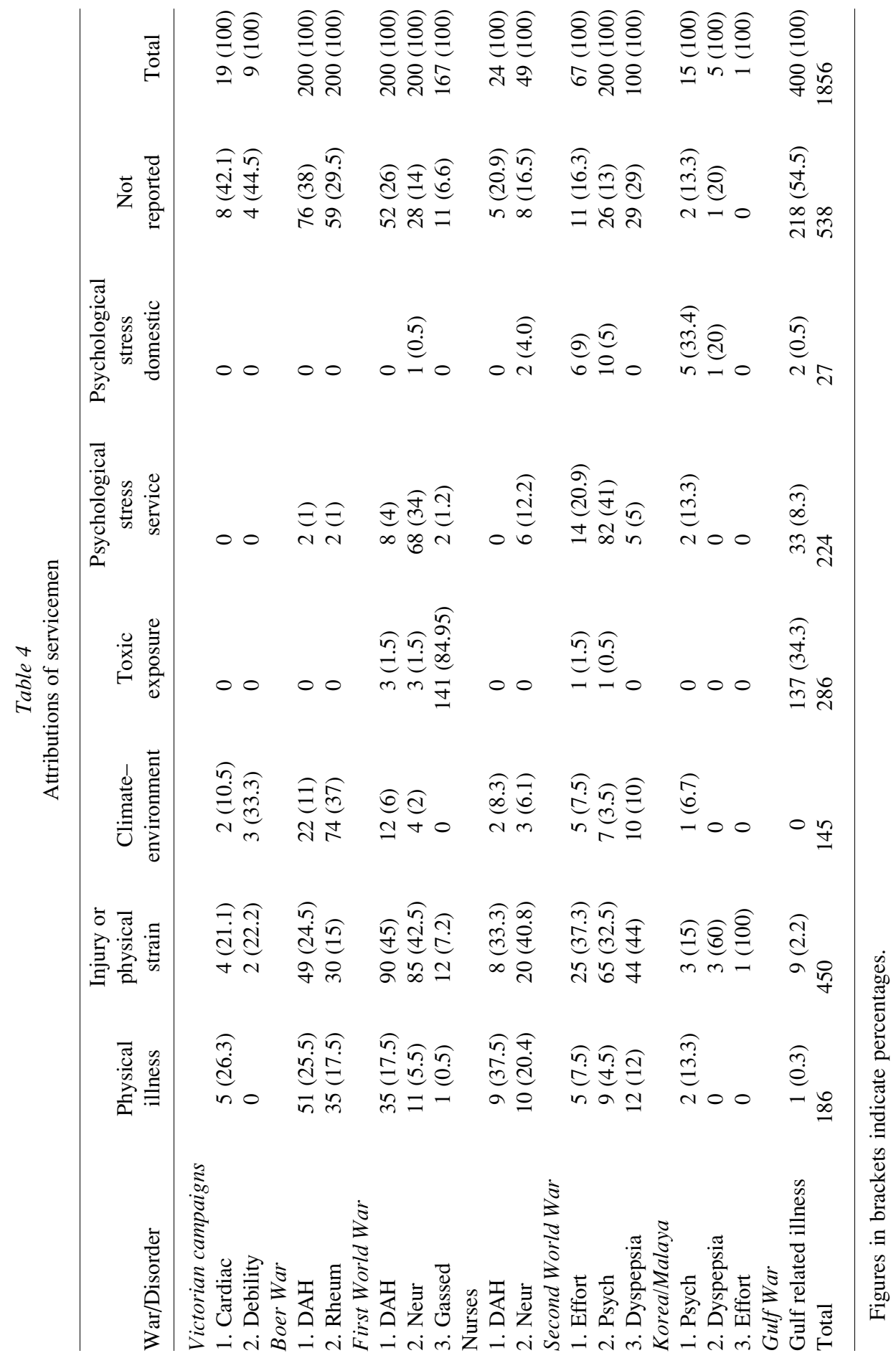




\section{Edgar Jones and Simon Wessely}

psychological stress of military service. They had, perhaps, been influenced by psychologically-minded physicians and the gradual incursion of psychiatric texts into medical and general literature.

The Second World War saw this process continue and 41.0 per cent of the neuropsychiatric sample attributed their symptoms to psychological stress arising from military service and a further 5 per cent to stresses related to their domestic situation. By contrast, 44.0 per cent of the dyspepsia population ascribed their symptoms to the physical exertions of active service, as did 37.3 per cent of the effort syndrome sample. Only 8.3 per cent of the Gulf War sample believed that stress played a causal role, while 34.3 per cent thought that their condition was the result of toxic exposure.

Contemporary attributions made by servicemen broadly correlated with the symptom characteristics of the three groups. In the debility cluster, 61.2 per cent believed that their illness was related either to a physical illness, physical injury/strain, climate or toxic exposure. By comparison, 143 (63.8 per cent) of the 224 who believed the psychological stress of military service was the cause of their illness came from the neuropsychiatric cluster. Equally, only 23 (12.4 per cent) of the 186 who believed that they were suffering from a physical illness were found in this group.

\section{Issues of Evidence}

Over the period covered by this study, terminology has changed and the same diagnostic term could subtly alter its meaning. ${ }^{96}$ However, data for this study was derived from contemporaneous accounts and limited to relatively straightforward symptoms such as headache, joint pain, chest pain, fatigue, difficulty sleeping, dizziness, tics, rashes, incontinence or shortness of breath. Some symptoms were verifiable such as palpitations, contractures, or changes in weight by measurement. Others, such as difficulty performing tasks, could be corroborated as police reports and evidence from employers were gathered. Nevertheless, Guenter Risse and John Harley Warner have shown that patient records "hardly provide a simple access to clinical reality" insofar as they reflect "the perceptions and interpretations of contemporary health care providers". 97 They will express the bias of the physician and reflect the culture of the period. As a result, it has to be acknowledged that some symptoms may have been given a different emphasis over the ninety years of this investigation.

However, there were some safeguards against the effects of bias. First, the use of war pension files containing repeated medical investigations sometimes over fifty years and by a number of doctors often with different backgrounds, militated against error or extreme opinions. Secondly, it was in the veteran's interest to describe his symptoms, as the award and level of his pension was based on the severity of his disability. Although this system may have encouraged some patients to exaggerate their illnesses, the pension authorities often required servicemen to provide corroborative evidence. In our study, the benefit of any doubt about the existence of a symptom was always given to the veteran.

\footnotetext{
${ }^{96}$ Shorter, op. cit., note 10 above, pp. 553-66.

${ }^{97} \mathrm{G}$ B Risse and J H Warner, 'Reconstructing clinical activities: patient records in
} medical history', Soc. Hist. Med., 1992, 5:
183-205, p. 204. 


\section{War Syndromes}

\section{Conclusion}

Although cultural factors influenced both the report of symptoms by patients and their recognition by doctors, the patterns manifested by war syndromes were not straightforward. Cluster analysis of ten diagnostic varieties of war syndrome did not identify sub-populations with a clear-cut bodily focus related to a particular war. For example, we did not discover a cluster solely characterized by gastro-intestinal symptoms limited to the Second World War, nor did we find a cluster of heart patients confined to the Boer War and the First World War. There was considerable symptom overlap between different formal diagnoses and between the same diagnosis recorded in different conflicts. Soldiers labelled with shell shock were found in both the somatic and neuropsychiatric clusters. Although veterans from the Gulf War were predominantly distributed in the neuropsychiatric cluster, they also fell within the somatic and debility clusters. This finding partly relates to the nature of functional somatic disorders. Because they are characterized by a range of common but non-specific symptoms, doctors were able to categorize them in a variety of ways, often according to their own speciality or interests. Although a specific association between formal diagnosis and symptoms did not exist, a general association between particular wars and clustering was identified. Most soldiers in the debility cluster, for example, were veterans of Victorian campaigns or the Boer War, while the neuropsychiatric cluster mainly contained men from the Second World War or Gulf conflict.

The continued presentation of functional somatic symptoms in contemporary medical practice also undermines the claim that psychosomatic causation has been driven to extinction by growing psychological understanding and sophistication. ${ }^{98}$ A recent study of primary care showed a minimum prevalence figure of 48 per 100,000 for conversion disorders, though the authors believed that this was an understatement of their true incidence. ${ }^{99}$ It is by no means clear that psychiatric explanations are significantly more acceptable than they were in the past. Furthermore, it has been suggested that the limited number of epidemiological investigations into hysteria has contributed to the impression that this remains a rare phenomenon. $^{100}$

The major cultural change to impact on war syndromes in the last quarter of the twentieth century appears to be a general fear of toxins spread as a result of modern industrial life. Of the 218 Gulf War veterans in our study who gave an explanation, 34.3 per cent believed that their condition was caused by some form of poisoning. By contrast, only 1.5 per cent of the effort syndrome sample and 0.5 per cent of the psychoneurosis sample drawn from Second World War veterans thought that toxic exposure was implicated. It is perhaps too early to say what were the key events in raising public consciousness although the thalidomide episode, the publication of Silent spring (1962)—Rachel Carson's investigation into the hazards of $\mathrm{DDT}^{101}$ - and environmental catastrophes such as Bhopal and Chernobyl attracted considerable media attention. Multiple chemical sensitivities (MCS) or "twentieth century disease" is perhaps the most extreme expression of this theme.

\footnotetext{
${ }^{98}$ E Slater, 'Diagnosis of "hysteria",, Br. med. J., 1965, ii: $1395-9$.

${ }^{99} \mathrm{~S}$ P Singh and A S Lee, 'Conversion disorders in Nottingham: alive, but not kicking', J. Psychosom. Res., 1997, 43: 425-30.
}

\footnotetext{
${ }^{100} \mathrm{H}$ Akagi and A House, 'The clinical epidemiology of hysteria: vanishingly rare, or just vanishing?', Psychol. Med., 2002, 32: 191-4.

${ }^{101} \mathrm{R}$ Carson, Silent spring, New York, Mariner Books, 1994.
} 


\section{Edgar Jones and Simon Wessely}

Whilst infection provided a powerful explanatory model in the first half of the twentieth century (suggested as a cause of rheumatism in the Boer War and DAH during the First World War), the development of effective anti-bacterial agents muted its impact. As a result, rituals of disinfection and measures to prevent contagion have become less prominent. Although the concept of surface violation and the need to maintain hygiene are no longer at the forefront of modern culture, they have been replaced by fears of internal threats to the immune system and the wish to ingest nothing that is not natural or pure. ${ }^{102}$

It is often stated that shell shock is the cultural predecessor of PTSD; in essence, the same disorder masquerading under a different name. ${ }^{103}$ By contrast, our findings suggest that shell shock is one example of a variety of functional somatic disorders that include effort syndrome, irritable heart, the effects of Agent Orange and Gulf War syndrome. In depth, cultural histories of these illnesses have yet to be written, though an attempt was recently made to re-interpret Gulf War syndrome as a modern form of soldier's heart. ${ }^{104}$ In understanding the true nature of war syndromes, it is important not only to acknowledge the debt to shell shock and the legacy of trauma but also to examine their expression as reflections of contemporary accounts of health and illness beyond the field of PTSD.

Our findings imply that the pathology of war syndromes is not static. Culture, along with advances in treatments, the discovery of new diseases, new diagnostic tools and the changing nature of warfare, plays a significant role in shaping patterns of symptoms. Paul Lerner and Mark Micale concluded that "national medical culture; political, legal, and economic factors; race, class, and gender - these are only a handful of the determining influences in the history of psychological trauma". ${ }^{105}$ There is no single way for human beings to respond to the terrifying events of war. Ian Hacking has suggested that transient psychological disorders are not only shaped by changing culture but that they provide a form of release that is not available elsewhere in the society in which they thrive. ${ }^{106}$ This would explain why functional somatic disorders remain relatively common and continue to evoke strong feelings in veterans. We suggest that war syndromes are an important phase in the evolving picture of man's reaction to adversity.

\footnotetext{
${ }^{102}$ E Martin, Flexible bodies: tracking immunity in American culture from the days of polio to the age of AIDS, Boston, Beacon Press, 1994.

${ }^{103}$ Dean, op. cit., note 14 above, p. 26; Joseph, Williams, and Yule, op. cit., note 15 above, p. 6.

${ }^{104} \mathrm{~J}$ Wheelwright, The irritable heart: the medical mystery of the Gulf War, New York, W W Norton, 2001.
}

\footnotetext{
${ }^{105}$ P Lerner and M S Micale, 'Trauma, psychiatry, and history', in M S Micale and P Lerner (eds), Traumatic pasts: history, psychiatry and trauma in the modern age, 1870-1930, Cambridge University Press, 2001, pp. 1-27, on p. 24.

${ }^{106}$ I Hacking, Mad travellers: reflections on the reality of transient mental illnesses, London, Free Association Books, 1998, pp. 1-2.
} 